Pure Appl. Chem., Vol. 75, No. 9, pp. 1231-1237, 2003.

(C) 2003 IUPAC

\title{
Use of organoboron halides in organic synthesis*
}

\author{
G. W. Kabalka ${ }^{\ddagger}$, Z. Wu, and Y. Ju \\ Departments of Chemistry and Radiology, University of Tennessee, Knoxville, TN \\ 37996-1600, USA
}

\begin{abstract}
Several new organic transformations have been achieved utilizing boron halide reagents. Aryl aldehydes are conveniently converted to gem-dichloromethylbenzenes using boron trichloride. Aryl aldehydes are alkylated by alkylboron chlorides in a Grignard-like fashion to generate the corresponding arylalkanols or alkylboron chlorides. Aryl aldehydes react with divinylboron halides (generated via the haloboration of alkynes) to produce 1,5-dihalo-1,4-dienes in excellent yields.
\end{abstract}

\section{INTRODUCTION}

As part of a study focused on diastereoselective reductions, we synthesized a variety of $\beta$-hydroxycarbonyl compounds via classic Aldol chemistry [1,2]. While examining the effectiveness of a series of Lewis acid catalysts; we discovered an unusual Aldol-Grob reaction sequence initiated by boron triflouride (Scheme 1) [3,4].

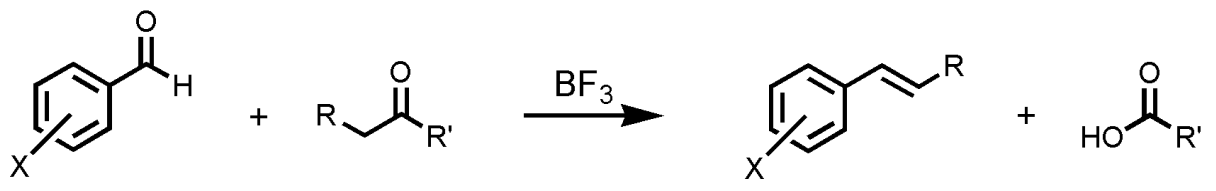

Scheme $1 \mathrm{BF}_{3}$-initiated Aldol-Grob reaction.

The reaction can also be utilized as a synthesis of carboxylic acids [5] as well as to create larger ring systems through sequential cleavage and alkylation reactions (Scheme 2) [6].<smiles>[R]C(C)=Cc1cccc([X])c1</smiles><smiles>[R]C1=Cc2ccccc2C(c2ccc([X])cc2[Y])C1</smiles>

Scheme $2 \mathrm{BF}_{3}$-initiated cleavage-condensation sequence.

\footnotetext{
${ }^{*}$ Lecture presented at the $\mathrm{XI}^{\text {th }}$ International Meeting on Boron Chemistry (IMEBORON XI), Moscow, Russia, 28 July-2 August 2002. Other presentations are published in this issue, pp. 1157-1355.

‡Corresponding author: E-mail: kabalka@utk.edu
} 
Interestingly, when we attempted to utilize boron trichloride in the new Aldol-Grob sequence, the reaction did not occur. Instead, dichlorophenylmethane derivatives were formed in excellent yields [7]. The reaction presumably occurs via the addition of boron and chlorine across the carbonyl bond, which is then followed by migration of a second chlorine from boron to carbon (Scheme 3). A similar reaction had been reported earlier for boron tribromide [8].<smiles>[X]c1ccc(C=O)cc1</smiles><smiles>[13CH3]C[GeH3]</smiles>

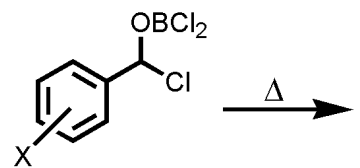<smiles>[X]c1ccc(C2(OB(Cl)CC)CCCCC2)cc1</smiles>

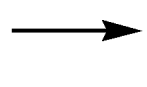<smiles>[X]c1ccc(C(Cl)Cl)cc1</smiles>

Scheme 3 Synthesis of dichlorophenylmethane.

This observation led us to consider the possibility that alkylboron halides might be utilized for Grignard-like addition reactions if an alkyl group could be made to transfer from boron to carbon in place of one of the chlorine atoms. The alkylation of carbonyl compounds by an organometallic reagent is an important method for assembling a variety of useful carbon skeletons. Generally, only reactive alkylmetals such as the organomagnesium [9], organolithium [10], organozinc [11], or organotransitionmetal reagents [12] can be utilized to achieve this transformation. Organoborane reagents such as the allylboranes, vinylboranes, and alkynylboranes have been used in many reactions involving the formation of new carbon-carbon bonds. However, saturated organoboranes are typically unreactive toward carbonyl compounds [13]. The earliest attempt at achieving a Grignard-like reaction using trialkylboranes involved simply mixing trialkylboranes and aldehydes and resulted in the reduction of the aldehydes via a $\beta$-hydrogen elimination [14]. Although the direct 1,2-addition of a trialkylborane to a carbonyl carbon is not readily achieved, certain modifications in either the carbonyl compound or the trialkylborane have led to a few successful alkylation reactions [15]. Certainly, a Grignard-like reaction involving organoborane reagents would possess a number of synthetic advantages including mild reaction conditions, stereochemical control, and the fact that a large number of functional substituents are unaffected in most organoborane transformations.

\section{METHODS AND RESULTS}

We first investigated the reaction of dichloroalkylboron reagents with aromatic aldehydes and discovered that no alkylation occurred; instead, mono- and dichlorophenylmethanes were formed (Scheme 4).

The formation of the dichloromethane product presumably occurs via the same mechanism involved when boron trichloride is utilized. The monochloromethane derivative almost certainly involves a $\beta$-hydrogen transfer [16] prior to, or after, the migration of one of the chlorine atoms. Interestingly,<smiles>[X]c1ccc(C=O)cc1</smiles>

Scheme 4 The reaction of dichloroalkylboron with aromatic aldehydes. 
we found that dialkylboron chloride derivatives would react with aromatic aldehydes to form the corresponding alkylphenylmethyl chlorides in moderate yields if the reaction mixtures were heated. Then, we discovered that the desired alkylation reaction could be achieved by simply adding a base to the reaction mixture (Scheme 5). The reaction produced good-to-excellent yields of the desired alkylphenylmethanols [16].<smiles>[X]c1ccc(C=O)cc1</smiles>

Scheme 5 Alkylation of aromatic aldehydes.

The yields were not dependent on the electronic nature of the substituent, X, but secondary alkyl groups migrated more efficiently than primary alkyl groups. The reaction presumably proceeds via displacement of a chlorine atom by the alkyl group (Scheme 6).
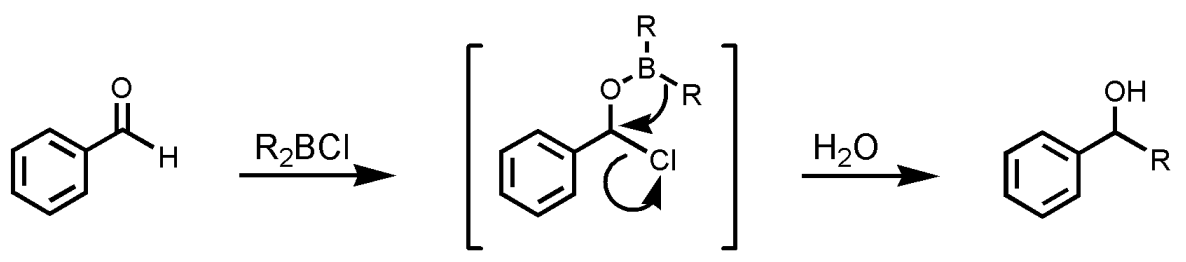

Scheme 6 Potential reaction mechanism.

We attempted to extend the reaction to the corresponding divinylboron halides (formed in situ), but discovered that the reaction took an entirely different course [17] (Scheme 7).



Scheme 7 Formation of Z,Z-dienes.

The products were essentially pure Z,Z isomers when boron tribromide was used to haloborate the phenyl acetylene but E,Z isomers predominated when boron trichloride was utilized. The diastereomeric differences are presumably due to differences in the stereochemistry of the corresponding haloboration reactions.

More recently, we discovered that alkylation reactions involving organoboron halides occur quite readily in the presence of oxygen (Scheme 8) [18]. Organoboranes are known to undergo autoxidation in the presence of oxygen, and the reaction has been used to prepare alcohols and alkyl hydroperoxides<smiles>[X]c1ccc(C=O)cc1</smiles>

Scheme 8 Alkylation of aromatic aldehydes in the presence of oxygen.

(C) 2003 IUPAC, Pure and Applied Chemistry 75, 1231-1237 
as well as to mediate free-radical reactions $[19,20]$. Trialkylboranes can also alkylate many $\alpha, \beta$-unsaturated carbonyl compounds through a radical 1,4-addition reaction in the presence of air [21]. Organoboranes do not normally undergo a 1,2-addition to saturated carbonyl compounds through radical reactions, with the exception of formaldehyde which was reported to react with trialkylboranes in the presence of air to produce the alkylation products [22]. The reaction is not a general one. However, we found that the reaction of dialkylboron chlorides with aromatic aldehydes was both efficient (isolated yields $\sim 90 \%$ ) and a wide variety of structural and electronic modifications were tolerated.

Although the mechanistic pathway of the alkylation of aldehydes is still not clear, based on current observations, the reaction appears to proceed through a radical chain mechanism (Scheme 9). These observations include the fact that the reactions were found to be extremely fast. Most importantly, in the presence of radical scavenger such as galvinoxyl, no alkylation occurred. In addition, in the case of alkylboranes containing primary alkyl groups, significant quantities of secondary isomers were formed. These results suggest the formation of radicals in the reaction.
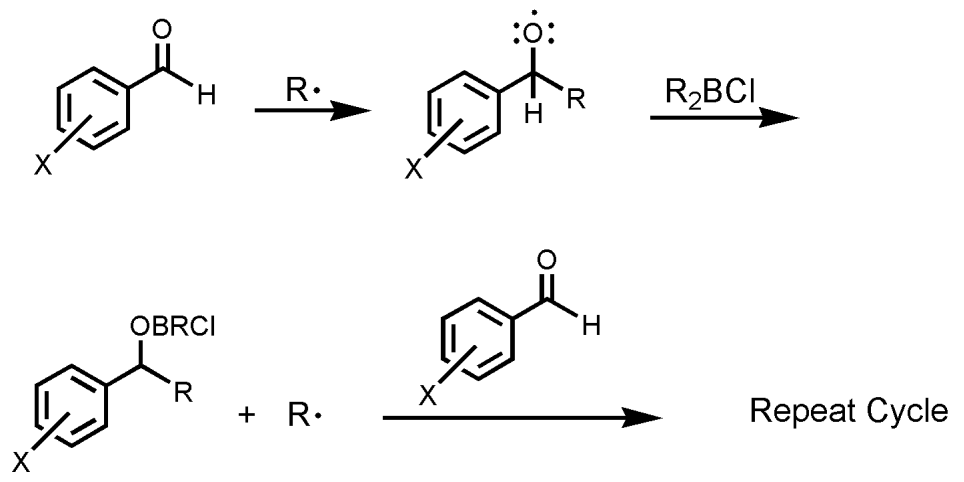

Scheme 9 Radical chain mechanism.

Representative examples are presented in Table 1.

Table 1 Synthesis of arylalkylmethanols via reactions of aryldehydes with $\mathrm{R}_{2} \mathrm{BCl}$ in the presence of oxygen.

\begin{tabular}{llc}
\hline $\mathrm{X}$ & \multicolumn{1}{c}{$\mathrm{R}$} & Yield $(\%)^{\mathrm{a}}$ \\
\hline $\mathrm{H}$ & Cyclohexyl & 90 \\
$4-\mathrm{F}$ & Cyclohexyl & 95 \\
$4-\mathrm{Cl}$ & Cyclohexyl & 98 \\
$2-\mathrm{Cl}$ & Cyclohexyl & 63 \\
$4-\mathrm{Me}$ & Cyclohexyl & 96 \\
$2-\mathrm{Me}$ & Cyclohexyl & 88 \\
$4-\mathrm{OMe}$ & Cyclohexyl & 98 \\
$\mathrm{Naphthyl}$ & Cyclohexyl & 94 \\
$1,4-(\mathrm{CHO})_{2}$ & Cyclohexyl & 84 \\
$4-\mathrm{CN}$ & Cyclohexyl & 92 \\
$\mathrm{H}$ & Norbornyl & 76 \\
$4-\mathrm{Br}$ & Norbornyl & 73 \\
$4-\mathrm{Me}$ & Norbornyl & 75 \\
$\mathrm{H}$ & sec-Butyl & 65 \\
$4-\mathrm{F}$ & sec-Butyl & 74 \\
$4-\mathrm{Cl}$ & sec-Butyl & 67 \\
$4-\mathrm{Br}$ & sec-Butyl & 70
\end{tabular}

(continues on next page) 
Table 1 (Continueed).

\begin{tabular}{llc}
\hline $\mathrm{X}$ & \multicolumn{1}{c}{$\mathrm{R}$} & Yield $(\%)^{\mathrm{a}}$ \\
\hline $4-\mathrm{Me}$ & sec-Butyl & 71 \\
$2-\mathrm{Me}$ & sec-Butyl & 55 \\
$\mathrm{H}$ & $n$-Hexyl & $84^{\mathrm{b}}$ \\
$4-\mathrm{Cl}$ & $n$-Hexyl & $75^{\mathrm{b}}$ \\
$4-\mathrm{Br}$ & $n$-Hexyl & $64^{\mathrm{b}}$ \\
$4-\mathrm{Me}$ & $n$-Hexyl & $72^{\mathrm{b}}$ \\
$2-\mathrm{Me}$ & n-Hexyl & $81^{\mathrm{b}}$ \\
\hline
\end{tabular}

${ }^{\mathrm{a}}$ Isolated yields based on starting aldehydes.

${ }^{\mathrm{b}}$ Significant quantities of the product containing the secondary alkyl group are formed.

Since only one of the alkyl groups in dialkylboron chlorides is transferred to the carbonyl, the reaction would be more efficient if monoalkylboron dichlorides could be utilized in the alkylation reaction. Thus, we examined the reaction of alkylboron dichlorides with aryl aldehydes in the presence of oxygen. Interestingly, instead of alkylarylmethanols, the reaction produced the chloroalkylation products exclusively at room temperature. It was noted that a small quantity of benzyl chloride was formed along with the desired alkylation products as has been observed in our earlier reports [23].

A series of aryl aldehydes were subjected to the reaction sequence. Essentially, all aldehydes examined were successfully converted to the corresponding arylalkyl chlorides (Scheme 10).
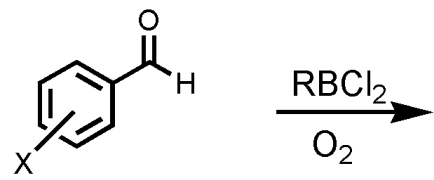<smiles>[X]c1ccc(C([R])Cl)cc1</smiles>

Scheme 10 Formation of 1-aryl-1-chloroalkanes.

To our surprise, in contrast to the reaction of $\operatorname{di}(n$-hexyl)boron chloride, secondary isomers were not observed in the reaction products when $n$-butylboron dichloride was allowed to react with aryl aldehydes. This suggests that the reaction of monoalkylboron dichlorides may proceed through a different reaction pathway than the free-radical mechanism postulated earlier for dialkylboron chlorides. In order to gain an insight into the reaction mechanism, one reaction was monitored by NMR spectroscopy. Benzaldehyde was mixed with one equivalent of $n$-butylboron dichloride in benzene- $\mathrm{d}_{6}$. It was observed that the ${ }^{1} \mathrm{H}$ and ${ }^{13} \mathrm{C}$ resonances of the carbonyl group were absent in the NMR spectra, and no new resonances were observed. Upon prolonging the reaction time, reductive chlorination of the aldehyde occurred, which led to formation of benzyl chloride. In a separate experiment, oxygen was introduced to the reaction mixture. The NMR spectra revealed that the chloroalkylation product, 1-phenylpentyl chloride, was gradually formed. Furthermore, the addition of a radical scavenger, galvinoxyl, did not inhibit the alkylation reaction. Therefore, we postulate that the reaction proceeds through the oxidation of the organoborane to form a peroxide intermediate. An alkyl transfer then occurs through an intramolecular six-membered ring transition state to give a borinate ester followed by migration of chlorine atom to afford the final product (Scheme 11). In order to confirm the possible presence of a peroxy intermediate, a reaction was carried out at $-20{ }^{\circ} \mathrm{C}$. No alkylation occurred, but $n$-butyl peroxide was isolated upon hydrolysis of the reaction mixture. 

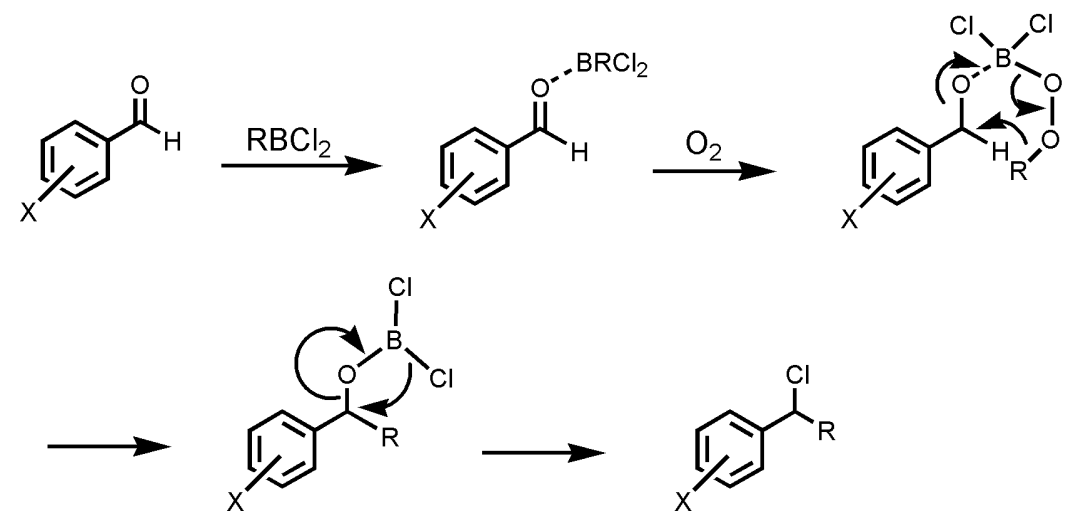

Scheme 11 Potential reaction mechanism.

\section{CONCLUSION}

The new alkylation reactions provide potentially useful alternatives to traditional Grignard and organolithium reactions. The reactions occur under mild conditions and tolerate a variety of functional groups. The dialkylboron chlorides react with aryl aldehydes to produce the corresponding alkylarylmethanols in excellent yields, whereas alkylboron dichlorides afford the alkylaryl chlorides in moderate-to-good yields. The reaction is limited to aldehydes, which do not possess $\beta$-hydrogens due to the well-known enolization reactions that occur with boron halides.

\section{REFERENCES}

1. C. Narayana, M. R. Reddy, M. Hair, G. W. Kabalka. Tetrahedron Lett. 38, 7705 (1997).

2. G. W. Kabalka, K. Yang, Z. Wang. Tetrahedron 31, 511 (2001).

3. G. W. Kabalka, D. Tejedor, N.-S. Li, R. R. Malladi, S. Trotman. J. Org. Chem. 63, 6438 (1998).

4. G. W. Kabalka, N.-S. Li, D. Tejedor, R. R. Malladi, S. Trotman. J. Org. Chem. 64, 3157 (1999).

5. G. W. Kabalka, N.-S. Li, D. Tejedor, R. R. Malladi, X. Gao, S. Trotman. Synth. Commun. 29, 2783 (1999).

6. R. R. Malladi, N.-S. Li, D. Tejedor, G. W. Kabalka. Synth. Commun. 30, 3613 (2000).

7. G. W. Kabalka and Z. Wu. Tetrahedron Lett. 41, 579 (2000).

8. J. M. Lansinger and R. C. Ronald. Synth. Comm. 9, 342 (1979).

9. (a) M. S. Kharasch and O. Reinmuth. Grignard Reactions of Non-Metallic Substances, PrenticeHall, New York (1954); (b) C. Blomberg and F. A. Hartog. Synthesis 18 (1977); (c) R. C. Larock. Comprehensive Organic Transformations, pp. 553-567, VCH, New York (1989); (d) J. B. Sweeny. Comprehensive Organic Functional Group Transformations, Vol. 2, A. R. Katrizky, O. Meth-Cohn, C. W. Rees, S. V. Ley (Eds.), p. 37, Pergamon, Cambridge (1995).

10. B. J. Wakefield. Organolithium Method, Academic Press, New York (1988).

11. (a) P. Knochel and R. D. Singer. Chem. Rev. 93, 2117 (1993); (b) J. Furukawa and N. Kawabata. Adv. Organomet. Chem. 12, 103 (1974).

12. (a) T. Kauffman, T. Abel, M. Schreer, D. Wingbermuhle. Tetrahedron 43, 2021 (1987); (b) M. T. Reetz, R. Steinbach, J. Westermann, R. Urz, B. Wenderoth, R. Peter. Angew. Chem., Int. Ed. 21, 135 (1982); (c) Y. Ikeda, J. Ukai, N. Ikeda, H. Yamamoto. Tetrahedron 43, 723 (1987); (d) S. Fukuzawa, T. Tsuchimoto, T. Tanai. Chem. Lett. 1981 (1994); (e) Y. Kataoka, I. Makihira, M. Utsunomiya, K. Tani. J. Org. Chem. 62, 8540 (1997). 
13. (a) E. Negishi. Organometallics in Organic Synthesis, Vol. 1, p. 304, Wiley-Interscience, New York (1980); (b) Y. Yamamoto and N. Asao. Chem. Rev. 93, 2207 (1993); (c) W. R. Roush and P. T. Grover. J. Org. Chem. 60, 3806 (1995); (d) H. C. Brown, R. A. Randad, K. S. Bhat, M. Zaidlewicz, U. S. Racherla. J. Am. Chem. Soc. 112, 2389 (1990); (e) R. A. Batey, D. G. Mackay, V. Santhakumar. J. Am. Chem. Soc. 121, 5075 (1999).

14. (a) B. M. Mikhailov, V. G. Kiselev, Y. N. Bubnov. Bull. Acad. Sci. USSR, Div. Chem. Sci. 865 (1965); (b) B. M. Mikhailov, Y. N. Bubnov, V. G. Kiselev. J. Gen. Chem. USSR 36, 65 (1966).

15. (a) G. W. Kabalka, J. T. Maddox, E. Bogas, S. Kelly. J. Org. Chem. 62, 3688 (1997); (b) K. Okada, Y. Hosoda, M. Oda. Tetrahedron Lett. 6213 (1986); (c) B. M. Mikhailov, T. K. Baryshnikova, A. S. Shashkov. J. Organomet. Chem. 219, 301 (1981).

16. G. W. Kabalka, Z. Wu, Y. Ju. Tetrahedron 57, 1663 (2001).

17. G. W. Kabalka, Z. Wu, Y. Ju. Org. Lett. 4, 1491 (2002).

18. G. W. Kabalka, Z. Wu, Y. Ju. Tetrahedron 58, 3243 (2002).

19. (a) H. C. Brown and M. M. Midland. Tetrahedron 43, 4059 (1987); (b) H. C. Brown, M. M. Midland, G. W. Kabalka. Tetrahedron 42, 5523 (1986).

20. (a) P. Devin, L. Fensterbank, M. Malacria. Tetrahedron Lett. 40, 4473 (1999); (b) H. Miyabe, M. Ueda, N. Yoshioka, T. Naito. Synlett 465 (1999).

21. (a) A. Suzuki, H. Matsumoto, M. Itoh, H. C. Brown, M. M. Rogic, M. W. Rathke. J. Am. Chem. Soc. 89, 5708 (1967); (b) C. Ollivier and P. Renaud. Chem. Eur. J. 5, 1568 (1999); (c) H. C. Brown, M. M. Rogic, M. W. Rathke, G. W. Kabalka. Intra-Sci. Chem. Rep. 7, 57 (1973).

22. N. Miyaura, M. Itoh, A. Suzuki, H. C. Brown, M. M. Midland, P. J. Jacob, III. J. Am. Chem. Soc. 94, 6549 (1972).

23. G. W. Kabalka, Z. Wu, Y. Ju. Tetrahedron Lett. 41, 5161 (2000). 